\title{
Glucocorticoid administration into the dorsal stratium facilitates memory consolidation of inhibitory avoidance training but not of the context or footshock components
}

\author{
Andrea C. Medina, ${ }^{1}$ Jonathan R. Charles, ${ }^{1,2}$ Verónica Espinoza-González, ${ }^{1}$ \\ Oscar Sánchez-Resendis, ${ }^{1}$ Roberto A. Prado-Alcalá, ${ }^{1}$ Benno Roozendaal, ${ }^{2}$ \\ and Gina L. Quirarte ${ }^{1,3}$ \\ ${ }^{1}$ Departamento de Neurobiología Conductual y Cognitiva, Instituto de Neurobiología, Universidad Nacional Autónoma de \\ México, Campus Juriquilla Querétaro 76230, México; ${ }^{2}$ Center for the Neurobiology of Learning and Memory, Department of \\ Neurobiology and Behavior, University of California, Irvine, CA 92697-3800, USA
}

\begin{abstract}
It is well established that glucocorticoid administration into a variety of brain regions facilitates memory consolidation of fear-conditioning tasks, including inhibitory avoidance. The present findings indicate that the natural glucocorticoid corticosterone administered into the dorsal striatum (i.e., caudate nucleus) of male Wistar rats produced dose- and time-dependent enhancement of inhibitory avoidance memory consolidation. However, as assessed with a modified inhibitory avoidance procedure that took place on two sequential days to separate context training from footshock training, corticosterone administration into the dorsal striatum did not enhance memory of either the contextual or aversively motivational aspects of the task.
\end{abstract}

Considerable evidence indicates that adrenocortical hormones facilitate the consolidation of long-term memories of emotionally arousing experiences by acting in a variety of brain regions (for reviews, see Sandi 1998; de Kloet et al. 1999; Roozendaal 2000; McGaugh and Roozendaal 2002). For example, glucocorticoids administered post-training into either the hippocampus or the basolateral amygdala enhance memory of fear-conditioning tasks, including inhibitory avoidance (Cottrell and Nakajima 1977; Roozendaal and McGaugh 1997a,b). However, recent findings indicate that glucocorticoid infusions into these two brain regions enhance memory consolidation of different aspects of information learned during inhibitory avoidance training. To assess the relative involvement of a brain region in memory consolidation of the contextual information independently from that of the footshock, we have used a modified inhibitory avoidance procedure in which context training alone and footshock training alone occur on two sequential days (Malin and McGaugh 2006). Consistent with extensive evidence that the hippocampus is involved in the learning of contextual information (Maren and Fanselow 1997; Sacchetti et al. 1999), a specific glucocorticoid receptor (GR) agonist administered into the hippocampus after context exposure enhanced the subsequent conditioning whereas infusions administered after the footshock training were ineffective (Roozendaal et al. 2008). In contrast, a GR agonist infused into the basolateral amygdala enhanced retention when administered after either the context or footshock training, consistent with extensive evidence that basolateral amygdala activity modulates memory for many different kinds of experiences (Roozendaal 2000; McGaugh 2004). Similar differential effects have been reported previously with infusions of a muscarinic agonist into these two brain regions (Malin and McGaugh 2006).

The dorsal striatum (i.e., caudate nucleus) is also involved in

\footnotetext{
${ }^{3}$ Corresponding author.
}

E-mail ginaqui@servidor.unam.mx; fax 52-442-238-4047

Article is online at http://www.learnmem.org/cgi/doi/10.1101/lm.654407. consolidation of inhibitory avoidance training. Since the 1960s, it has been recognized that lesions of the dorsal striatum or pharmacological manipulations of striatal function modulate inhibitory avoidance memory (Kirkby and Kimble 1968; Haycock et al. 1973; Prado-Alcalá et al. 1975, 1980, 2003; Pérez-Ruíz and PradoAlcalá 1989; Chavez et al. 1995). Although GRs are known to be moderately expressed in the dorsal striatum (Defiore and Turner 1983; Ahima and Harlan 1990, 1991; Morimoto et al. 1996) and glucocorticoids alter the activity of several neurotransmitter and receptor systems in this brain region (Kaufman et al. 1988; Mailleux and Vanderhaeghen 1993; Ngai and Herbert 2005), studies have not, as yet, investigated whether glucocorticoids administered into the dorsal striatum modulate memory consolidation. To investigate this issue, a first experiment examined whether post-training intra-striatal administration of corticosterone (i.e., the rat's natural glucocorticoid) enhanced memory consolidation of inhibitory avoidance training. A second experiment used the modified, two-phase inhibitory avoidance procedure to examine whether corticosterone administration into the dorsal striatum might specifically strengthen memory of either the context or footshock experience. All experimental procedures were approved by the Animal Ethics Committee of Instituto de Neurobiología, Universidad Nacional Autónoma de México, and were in compliance with the NIH Guide for Care and Use of Laboratory Animals.

Adult male Wistar rats (250-350 g at the time of surgery), obtained from the breeding colony at the Instituto de Neurobiología, Universidad Nacional Autónoma de México, were kept individually in a temperature-controlled $\left(24^{\circ} \mathrm{C}\right)$ colony room and maintained on a standard 12-h light/12-h dark cycle (07:0019:00 $\mathrm{h}$ lights on) with ad libitum access to food and water. They were implanted under sodium pentobarbital anesthesia $(50 \mathrm{mg} /$ $\mathrm{kg}$, i.p.) with bilateral guide cannulae (11 mm long; 23 gauge) aimed at the anterior division of the dorsal striatum [coordinates: anteroposterior, $0.0 \mathrm{~mm}$ from bregma; mediolateral, $\pm 3.2 \mathrm{~mm}$ from midline; dorsoventral, $-4.3 \mathrm{~mm}$ from skull surface] according to the atlas of Paxinos and Watson (1998). To control for 
site-specificity, other rats received bilateral cannulae aimed at the parietal cortex, using identical coordinates as those for the dorsal striatum, except that the cannulae were lowered only $0.5 \mathrm{~mm}$ below skull surface. The rats were allowed to recover $7 \mathrm{~d}$ before initiation of training and were accustomed to the handling procedure on each of $3 \mathrm{~d}$ before the training session.

For all experiments, the rats were trained in an inhibitory avoidance apparatus, consisting of a trough-shaped alley $(60 \mathrm{~cm}$ long, $25 \mathrm{~cm}$ deep, $20 \mathrm{~cm}$ wide at the top, $8 \mathrm{~cm}$ wide at the floor) divided into two compartments, separated by a guillotine door. The starting compartment (30 cm long) had walls and lid made of red-colored acrylic with a floor of stainless steel bars (diameter $6 \mathrm{~mm}$; spaced $9 \mathrm{~mm}$ apart) and was well lit. The shock compartment (30 cm long) was made of two electrifiable stainless steel plates and was not illuminated. For one-trial inhibitory avoidance training, the rat was placed into the lighted compartment; $10 \mathrm{sec}$ later the sliding door was opened, and the latency to enter the dark compartment was recorded. After the animal stepped into the shock compartment with all four paws, the door was closed and a single, inescapable footshock $(0.45 \mathrm{~mA})$ was delivered for 1 sec using a precision-regulated shock generator (Coulbourn Instruments). For the modified, two-phase inhibitory avoidance procedure, on the first day (context training), the rat was placed into the starting compartment and allowed to freely explore the inhibitory avoidance apparatus for $3 \mathrm{~min}$. On day 2 (shock training), each rat was placed into the dark compartment, facing away from the starting compartment, with the retractable door closed. The rat then received an inescapable footshock (1.3 $\mathrm{mA}$ for $1 \mathrm{sec}$ ) and immediately afterward was removed from the training apparatus. Prior findings indicated that this footshock training alone does not induce significant cross-over latencies on a retention test (Roozendaal et al. 2008). Retention was always tested $48 \mathrm{~h}$ after training by placing the rat into the starting compartment of the inhibitory avoidance apparatus and measuring the latency to enter the former shock compartment. Longer latencies were indicative of better retention. If an animal did not cross into the shock compartment within $600 \mathrm{sec}$, the session was ended and a retention score of 600 was assigned.

For the first experiment, corticosterone $(5,10,20,30$, or 60 ng; Sigma) was administered into the dorsal striatum immediately or 30 or $60 \mathrm{~min}$ after training. Other animals received immediate post-training infusions of the GR antagonist RU 38486 (mifepristone, $1.0 \mathrm{ng}$; Sigma) into the dorsal striatum followed by an administration of either vehicle or corticosterone (10 ng). Rats trained on the modified inhibitory avoidance task received intrastriatal infusions of corticosterone (10 or $20 \mathrm{ng}$ ) immediately after either the context or shock training. Corticosterone and RU 38486 were first dissolved in 100\% ethanol and subsequently diluted in saline to reach the appropriate concentration. The final concentration of ethanol was $2 \%$. Bilateral infusions of drug or an equivalent volume or vehicle ( $2 \%$ ethanol in saline) into the dorsal striatum were made by using 30-gauge injection needles connected to $10-\mu \mathrm{L}$ Hamilton microsyringes with polyethylene tubing. The injection needle protruded $1.0 \mathrm{~mm}$ beyond the tip of the cannula and a $1.0-\mu \mathrm{L}$ injection volume per hemisphere was infused over a period of 60 sec by an automated syringe pump (WPI, model 220i). The injection needles were retained within the guide cannulae for an additional $60 \mathrm{sec}$ to maximize diffusion away from the injector tip.
Upon completion of behavioral testing, the rats were anesthetized with an overdose of sodium pentobarbital and perfused intracardially with isotonic saline followed by $4 \%$ formaldehyde. After decapitation, the brains were removed and immersed in a $4 \%$ formaldehyde solution. Coronal sections of $50 \mu \mathrm{m}$ were cut on a cryostat, stained with cresyl violet, and examined under a light microscope by an observer blind to drug-treatment condition. Figure 1 shows the location of injection needle tips in the dorsal striatum of rats trained on the one-trial inhibitory avoidance task. Histological examination of the second experiment revealed similar results (data not shown). Sixteen rats with improper injection needle placements were excluded from statistical analysis.

Figure 2A shows the findings of the first experiment investigating whether immediate post-training infusions of corticosterone into the dorsal striatum enhance memory of one-trial inhibitory avoidance training. Kruskal-Wallis nonparametric tests for step-through latencies during training, i.e., before footshock or drug treatment, revealed no significant differences between groups $(\mathrm{H}(6)=3.39, P=0.76$; data not shown). Forty-eight-hour retention latencies of rats infused with vehicle were significantly longer than their latencies during the training trial (Wilcoxon: $U=0, P<0.005)$, indicating that the rats retained memory of the shock experience. Post-training infusions of corticosterone induced dose-dependent retention enhancement (Kruskal-Wallis: $\mathrm{H}(6)=14.59, P=0.02$ ). Rats infused with the 10-ng dose of corticosterone showed significantly longer retention latencies compared to those treated with vehicle (Mann-Whitney $U$ test: $U=27, P<0.05$ ). Lower (5 ng) or higher (20 and $30 \mathrm{ng}$ ) doses did not induce retention enhancement, whereas the highest dose $(60$ ng) of corticosterone produced a significant retention impairment $(U=22, P<0.05)$. Infusion of the 10-ng dose of corticosterone into the parietal cortex, located immediately dorsal to the dorsal striatum, did not enhance retention, indicating that the memory enhancement produced by the dorsal striatum infusions was not caused by any upward diffusion of the drug along the cannula track.

As corticosterone was administered after the training trial, the retention performance effects cannot be attributed to nonspecific influences of the drug on acquisition such as changes in gross movement, a behavior controlled by the dorsal striatum (Hauber 1998). To examine further whether corticosterone administration into the dorsal striatum enhances inhibitory avoidance retention by strengthening the consolidation phase of memory processing, other groups of rats received corticosterone (10 ng) administered into the dorsal striatum immediately or 30 or 60 min after training. As shown in Figure 2B, rats microinjected with corticosterone immediately or $30 \mathrm{~min}$ after training

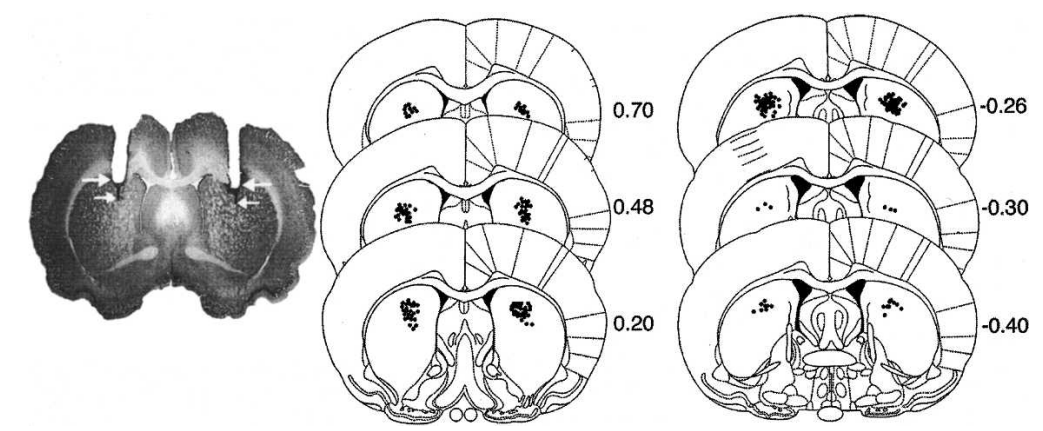

Figure 1. Photomicrograph and diagrams illustrating placement of the injection needle tips within the dorsal striatum of rats trained on the inhibitory avoidance task. Large arrows point to the cannula tips, and small arrows point to the injection needle tips. Coordinates are shown in $\mathrm{mm}$ from Bregma. Diagrams are redrawn from Paxinos and Watson (1998). 

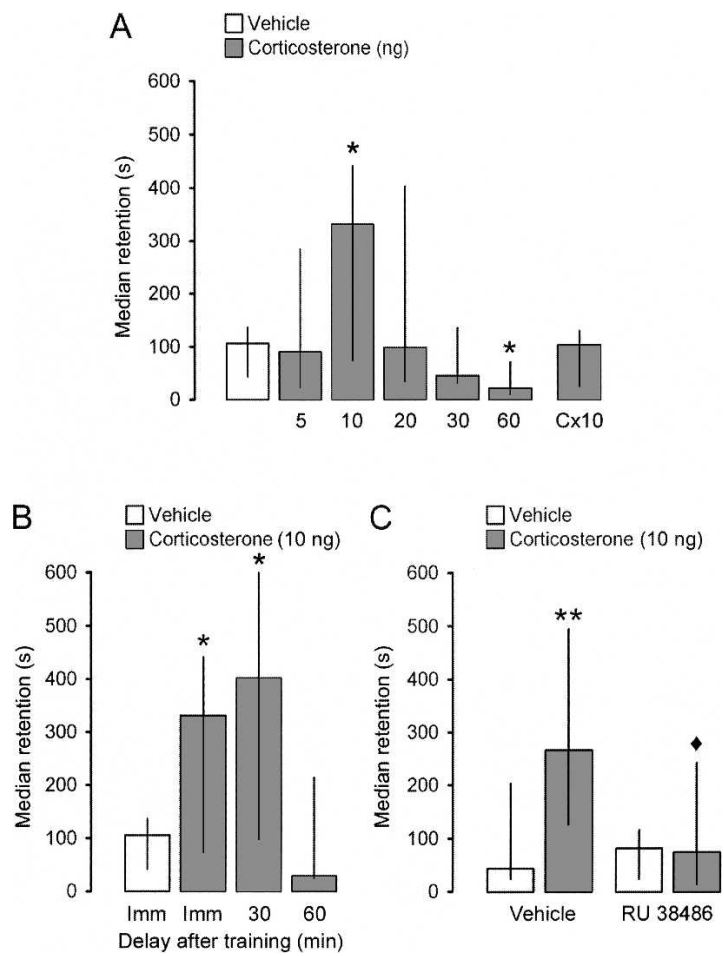

Figure 2. Effect of post-training infusions of corticosterone into the dorsal striatum on memory consolidation of one-trial inhibitory avoidance training. Data represent 48-h retention latencies in seconds as median and interquartile ranges. $(A)$ Rats received immediate post-training infusions of either vehicle or corticosterone into the dorsal striatum (5, $10,20,30$, or $60 \mathrm{ng}$ in $1.0 \mu \mathrm{L})$ or parietal cortex $(\mathrm{Cx}, 10 \mathrm{ng}) .{ }^{*} P<0.05$ as compared to vehicle. (B) Rats received corticosterone (10 $\mathrm{ng}$ ) immediately $(\mathrm{Imm}), 30 \mathrm{~min}$, or $60 \mathrm{~min}$ after training. ${ }^{*} P<0.05$ as compared to vehicle. (C) Rats received corticosterone $(10 \mathrm{ng})$ alone or together with the GR antagonist RU $38486(1 \mathrm{ng}) .{ }^{* *} P<0.01$ as compared to vehicle; $\checkmark, P<0.05$ as compared to the vehicle-corticosterone group. $N=7-11$ rats/group.

had significantly longer retention scores than those given vehicle immediately after training (Mann-Whitney $U$ tests: immediate, $U=27, P<0.05 ; 30 \mathrm{~min}, U=19, P<0.05$ ). However, corticosterone infused $60 \mathrm{~min}$ after training did not induce significant retention enhancement. These findings are consistent with those of previous experiments examining the effect of peripherally administered glucocorticoids (Flood et al. 1978; Sandi and Rose 1997) and indicate that the intra-striatal corticosterone administration enhanced retention by affecting time-dependent processes underlying long-term memory consolidation.

Corticosterone can bind to two types of adrenal steroid receptors in the brain: the low-affinity GR and the high-affinity mineralocorticoid receptor (Reul and de Kloet 1985; de Kloet et al. 1993). Glucocorticoid effects on memory consolidation appear to selectively involve an activation of GRs (Oitzl and de Kloet 1992; Roozendaal et al. 1996; Conrad et al. 1999). In situ hybridization and histochemical studies have reported that the dorsal striatum expresses GRs (Ahima and Harlan 1990, 1991; Morimoto et al. 1996) but is devoid of mineralocorticoid receptors (Agarwal et al. 1993). To determine whether the enhancing effect of corticosterone administration into the dorsal striatum on memory consolidation is mediated by GR activation, we examined whether intra-striatal administration of the GR antagonist RU 38486 blocked the facilitating effect of corticosterone on inhibitory avoidance memory. Kruskal-Wallis ANOVA for retention latencies revealed significant differences between groups
$(\mathrm{H}(3)=10.80, P=0.01)$. As is shown in Figure $2 \mathrm{C}$, rats treated with corticosterone (10 ng) had significantly longer retention latencies than the vehicle group (Mann-Whitney $U$ test: $U=9$, $P<0.01$ ), but coadministration of RU 38486 (1.0 ng) blocked this retention enhancement $(U=22, P<0.05)$. These findings indicate that corticosterone administration into the dorsal striatum enhances memory consolidation via an activation of GRs.

The last experiment used the modified inhibitory avoidance procedure that took place on two sequential days to investigate whether corticosterone administration into the dorsal striatum may enhance the consolidation of memory of either the context or footshock components of inhibitory avoidance training. Kruskal-Wallis ANOVAs for retention latencies did not reveal significant differences between groups administered corticosterone after either context $(\mathrm{H}(2)=2.68, P=0.3)$ or footshock $(\mathrm{H}(2)$ $=3.69, P=0.2$ ). As is shown in Figure 3 , retention latencies of rats given intra-striatal infusions of corticosterone (10 or $20 \mathrm{ng}$ ) immediately after context or footshock training did not differ from those of their corresponding vehicle groups. These findings indicate that corticosterone administered into the dorsal striatum does not enhance the consolidation of memory of inhibitory avoidance training by strengthening the memory of either the context or footshock components of the task when they occurred alone.

Thus, the present findings indicating that corticosterone administered into the dorsal striatum induced dose- and timedependent enhancement of inhibitory avoidance memory via an activation of GRs are consistent with extensive evidence indicating that post-training administration of corticosterone or specific GR agonists infused into the hippocampus or basolateral amygdala induces comparable enhancement of consolidation of inhibitory avoidance memory (Roozendaal 2000). However, prior research using the modified inhibitory avoidance procedure revealed that these brain regions are involved in mediating glucocorticoid effects on memory of specific aspects of information acquired during the training (Roozendaal et al. 2008). As indicated, we previously found that the hippocampus is selectively involved in mediating glucocorticoid effects on memory of the contextual component of inhibitory avoidance training whereas the basolateral amygdala, via its widespread projections to other brain regions, including the hippocampus and dorsal striatum (Packard et al. 1994), is more liberally involved in modulating the consolidation of memory for different kinds of experiences. An important finding of the present study is that striatal GR activation does not appear to be involved in processing memory of either context or footshock when presented separately.

Why do intra-striatal infusions of glucocorticoids enhance

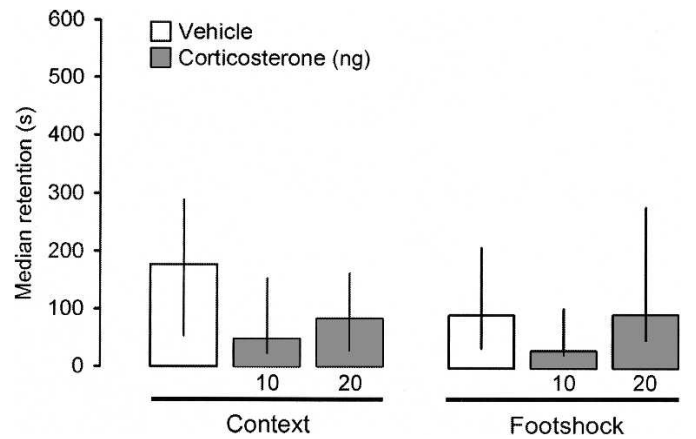

Figure 3. No effect of corticosterone (10 or $20 \mathrm{ng}$ in $1.0 \mu \mathrm{L}$ ) administered into the dorsal striatum immediately after training on the modified inhibitory avoidance task on memory for either context or footshock. Data represent 48-h retention latencies in seconds as median and interquartile ranges. $N=8-13$ rats/group. 
memory of one-trial inhibitory avoidance training but not of either the contextual or shock component of the task when they are not presented together? As corticosterone infused into the dorsal striatum does not enhance memory of the contextual components of training, in contrast with the effects of hippocampus infusions, it seems unlikely that the effects are mediated by GR activation in the dorsomedial part of the dorsal striatum, a brain region reported to support hippocampus-based memories (Devan et al. 1999; Featherstone and McDonald 2004). Extensive evidence indicates that the dorsolateral division of the dorsal striatum is involved in nondeclarative/implicit (i.e., stimulusresponse) forms of learning (Packard and White 1991; Packard et al. 1994; Packard and Knowlton 2002), but such a strengthening of stimulus-response associations also does not provide a satisfactory explanation of the present findings. Although the inhibitory avoidance task is often considered to be a spatial/contextual task in which animals learn to associate a place in the apparatus with footshock, rats may also learn that their behavioral response of stepping into the shock compartment is followed by punishment. In contrast, in the modified inhibitory avoidance task no movement is required, as the rats are placed directly into the shock compartment. As the dorsal striatum plays a dominant role in controlling movement (Hauber 1998), the post-training administration of corticosterone into the dorsal striatum may have enhanced inhibitory avoidance memory by specifically strengthening the memory of movement or its consequences. Accordingly, early findings indicated that lesions of the dorsal striatum impair memory of step-through inhibitory avoidance (PradoAlcalá et al. 1975) but not of Pavlovian fear conditioning, a task that differs from inhibitory avoidance in that the rats, as with the modified inhibitory avoidance procedure, are placed directly into the training context prior to shock administration (ReyesVazquez et al. 1979). Thus, the present findings suggest that glucocorticoids may strengthen not only the consolidation of memory of hippocampus-dependent declarative/explicit information, but also act in the dorsal striatum to enhance nondeclarative/implicit forms of memory. Preliminary findings investigating corticosterone effects in the dorsal striatum on memory consolidation of water-maze training are consistent with this view, as such infusions selectively enhanced memory of training on a cued, and not spatial, version of the task (G.L. Quirarte, unpubl.).

\section{Acknowledgments}

We thank Norma Serafín, Angel Méndez, Ma. del Pilar Galarza, Leopoldo Sánchez, Nidia E. Hernández, and Martín García for their excellent technical assistance. Supported by grants UC-MEXUS CN-06-77 (G.L.Q. and B.R.), DGAPA-PAPIIT-UNAM (IX22704 and IN208803), CONACYT U46754-Q (G.L.Q. and R.P.A.), National Science Foundation IOB-0618211 (B.R.), Graduate Fellowships (A.C.M. and O.S.R.) from CONACyT and DGEP, and Minority Health and Health Disparities International Research Training (J.R.C.), NIH MD-01485.

\section{References}

Agarwal, M.K., Mirshahi, F., Mirshahi, M., and Rostene, W. 1993. Immunochemical detection of the mineralocorticoid receptor in rat brain. Neuroendocrinology 58: 575-580.

Ahima, R.S. and Harlan, R.E. 1990. Charting of type II glucocorticoid receptor-like immunoreactivity in the rat central nervous system. Neuroscience 39: 579-604.

Ahima, R.S. and Harlan, R.E. 1991. Differential corticosteroid regulation of type II glucocorticoid receptor-like immunoreactivity in the rat central nervous system: Topography and implications. Endocrinology 129: $226-236$.

Chavez, M.E., Salado-Castillo, R., Sanchez-Alavez, M., Quirarte, G.L., and Prado-Alcalá, R.A. 1995. Post-training injection of GABAergic antagonists into the striatum produces retrograde amnesia. Neurobiol. Learn. Mem. 63: 296-300.
Conrad, C.D., Lupien, S.J., and McEwen, B.S. 1999. Support for a bimodal role for type II adrenal steroid receptors in spatial memory. Neurobiol. Learn. Mem. 72: 39-46.

Cottrell, G.A. and Nakajima, S. 1977. Effect of corticosteroids in the hippocampus on passive avoidance behavior in the rat. Pharmacol. Biochem. Behav. 7: 277-280.

Defiore, C.H. and Turner, B.B. 1983. $\left[{ }^{3} \mathrm{H}\right]$ Corticosterone binding in the caudate-putamen. Brain Res. 278: 93-101.

de Kloet, E.R., Oitzl, M.S., and Jöels, M. 1993. Functional implications of brain corticosteroid receptor diversity. Cell. Mol. Neurobiol. 13: $433-455$.

de Kloet, E.R., Oitzl, M.S., and Jöels, M. 1999. Stress and cognition: Are corticosteroids good or bad guys? Trends Neurosci. 22: 422-426.

Devan, B.D., McDonald, R.J., and White, N.M. 1999. Effects of medial and lateral caudate-putamen lesions on place- and cue-guided behaviors in the water maze: Relation to thigmotaxis. Behav. Brain Res. 100: 5-14.

Featherstone, R.E. and McDonald, R.J. 2004. Dorsal striatum and stimulus-response learning: Lesions of the dorsolateral, but not dorsomedial, striatum impair acquisition of a stimulus-response-based instrumental discrimination task, while sparing conditioned place preference learning. Neuroscience 124: $23-31$.

Flood, J.F., Vidal, D., Bennett, E.L., Orme, A.E., Vasquez, S., and Jarvik, M.E. 1978. Memory facilitating and anti-amnesic effects of corticosteroids. Pharmacol. Biochem. Behav. 8: 81-87.

Hauber, W. 1998. Involvement of basal ganglia transmitter systems in movement initiation. Prog. Neurobiol. 56: 507-540.

Haycock, J.W., Deadwyler, S.A., Sideroff, S.I., and McGaugh, J.L. 1973. Retrograde amnesia and cholinergic systems in the caudate-putamen complex and dorsal hippocampus of the rat. Exp. Neurol. 41: 201-213.

Kaufman, H., Vadasz, C., and Lajtha, A. 1988. Effects of estradiol and dexamethasone on choline acetyltransferase activity in various rat brain regions. Brain Res. 453: 389-392.

Kirkby, R.J. and Kimble, D.P. 1968. Avoidance and escape behavior following striatal lesions in the rat. Exp. Neurol. 20: 215-227.

Mailleux, P. and Vanderhaeghen, J.J. 1993. Glucocorticoid regulation of cannabinoid receptor messenger RNA levels in the rat caudate-putamen. An in situ hybridization study. Neurosci. Lett. 156: $51-53$.

Malin, E.L. and McGaugh, J.L. 2006. Differential involvement of the hippocampus, anterior cingulate cortex, and basolateral amygdala in memory for context and footshock. Proc. Natl. Acad. Sci. 103: 1959-1963.

Maren, S. and Fanselow, M.S. 1997. Electrolytic lesions of the fimbria/fornix, dorsal hippocampus, or entorhinal cortex produce anterograde deficits in contextual fear conditioning in rats. Neurobiol. Learn. Mem. 67: 142-149.

McGaugh, J.L. 2004. The amygdala modulates the consolidation of memories of emotionally arousing experiences. Annu. Rev. Neurosci. 27: 1-28.

McGaugh, J.L. and Roozendaal, B. 2002. Role of adrenal stress hormones in forming lasting memories in the brain. Curr. Opin. Neurobiol. 12: $205-210$.

Morimoto, M., Morita, N., Ozawa, H., Yokoyama, K., and Kawata, M. 1996. Distribution of glucocorticoid receptor immunoreactivity and mRNA in the rat brain: An immunohistochemical and in situ hybridization study. Neurosci. Res. 26: 235-269.

Ngai, L.Y. and Herbert, J. 2005. Glucocorticoid enhances the neurotoxic actions of quinolinic acid in the striatum in a cell-specific manner. $J$. Neuroendocrinol. 17: 424-434.

Oitzl, M.S. and de Kloet, E.R. 1992. Selective corticosteroid antagonists modulate specific aspects of spatial orientation learning. Behav. Neurosci. 106: 62-71.

Packard, M.G. and Knowlton, B.J. 2002. Learning and memory functions of the basal ganglia. Annu. Rev. Neurosci. 25: 563-593.

Packard, M.G. and White, N.M. 1991. Dissociation of hippocampus and caudate nucleus memory systems by posttraining intracerebral injection of dopamine agonists. Behav. Neurosci. 105: 295-306.

Packard, M.G., Cahill, L., and McGaugh, J.L. 1994. Amygdala modulation of hippocampal-dependent and caudate nucleus-dependent memory processes. Proc. Natl. Acad. Sci. 91: $8477-8481$.

Paxinos, G. and Watson, C. 1998. The rat brain in stereotaxic coordinates. Academic Press, San Diego.

Pérez-Ruíz, C. and Prado-Alcalá, R.A. 1989. Retrograde amnesia induced by lidocaine injection into the striatum: Protective effect of the negative reinforcer. Brain Res. Bull. 22: 599-603.

Prado-Alcalá, R.A., Grinberg, Z.J., Arditti, Z.L., Garcia, M.M., Prieto, H.G., and Brust-Carmona, H. 1975. Learning deficits produced by chronic and reversible lesions of the corpus striatum in rats. Physiol. 
Behav. 15: 283-287.

Prado-Alcalá, R.A., Cruz-Morales, S.E., and Lopez-Miro, F.A. 1980. Differential effects of cholinergic blockade of anterior and posterior caudate nucleus on avoidance behaviors. Neurosci. Lett. 18: 339-345.

Prado-Alcalá, R.A., Ruiloba, M.I., Rubio, L., Solana-Figueroa, R., Medina, C., Salado-Castillo, R., and Quirarte, G.L. 2003. Regional infusions of serotonin into the striatum and memory consolidation. Synapse 47: 169-175.

Reul, J.M. and de Kloet, E.R. 1985. Two receptor systems for corticosterone in rat brain: Microdistribution and differential occupation. Endocrinology 117: 2505-2511.

Reyes-Vazquez, C., Ibarra, T., and Brust-Carmona, H. 1979. Persistence of classical conditioned heart rate after extensive lesions of the striatum in rats. Physiol. Behav. 22: 1101-1105.

Roozendaal, B. 2000. Glucocorticoids and the regulation of memory consolidation. Psychoneuroendocrinology 25: 213-238.

Roozendaal, B. and McGaugh, J.L. 1997a. Glucocorticoid receptor agonist and antagonist administration into the basolateral but not central amygdala modulates memory storage. Neurobiol. Learn. Mem. 67: 176-179.

Roozendaal, B. and McGaugh, J.L. 1997b. Basolateral amygdala lesions block the memory-enhancing effect of glucocorticoid administration in the dorsal hippocampus of rats. Eur. J. Neurosci. 9: 76-83.
Roozendaal, B., Portillo-Marquez, G., and McGaugh, J.L. 1996. Basolateral amygdala lesions block glucocorticoid-induced modulation of memory for spatial learning. Behav. Neurosci. 110: $1074-1083$.

Roozendaal, B., Barsegyan, A., and Lee, S.K. 2008. Adrenal stress hormones, amygdala activation, and memory for emotionally arousing experiences. In Progress in brain research (eds. E.R. de Kloet et al.), Vol. 16, pp. 71-89. Elsevier, Amsterdam.

Sacchetti, B., Lorenzini, C.A., Baldi, E., Tassoni, G., and Bucherelli, C. 1999. Auditory thalamus, dorsal hippocampus, basolateral amygdala, and perirhinal cortex role in the consolidation of conditioned freezing to context and to acoustic conditioned stimulus in the rat. J. Neurosci. 19: 9570-9578.

Sandi, C. 1998. The role and mechanisms of action of glucocorticoid involvement in memory storage. Neural Plast. 6: 41-52.

Sandi, C. and Rose, S.P. 1997. Training-dependent biphasic effects of corticosterone in memory formation for a passive avoidance task in chicks. Psychopharmacology 133: 152-160.

Received May 30, 2007; accepted in revised form August 10, 2007. 


\section{Erratum}

Learning \& Memory 14: 673-677 (2007)

Glucocorticoid administration into the dorsal stratium facilitates memory consolidation of inhibitory avoidance training but not of the context or footshock components

Andrea C. Medina, Jonathan R. Charles, Verónica Espinoza-González, Oscar Sánchez-Resendis, Roberto A. Prado-Alcalá, Benno Roozendaal, and Gina L. Quirarte

Due to a typographical error, the word "stratium" in the title of this paper should be "striatum" instead. We apologize for any confusion this may have caused. 

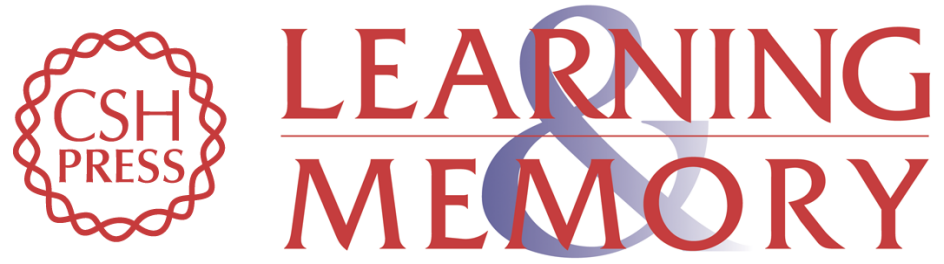

\section{Glucocorticoid administration into the dorsal stratium facilitates memory consolidation of inhibitory avoidance training but not of the context or footshock components}

Andrea C. Medina, Jonathan R. Charles, Verónica Espinoza-González, et al.

Learn. Mem. 2007, 14:

Access the most recent version at doi:10.1101//m.654407

Related Content Erratum

Learn. Mem. November , 2007 14: 703

References This article cites 41 articles, 3 of which can be accessed free at: http://learnmem.cshlp.org/content/14/10/673.full.html\#ref-list-1

Articles cited in:

http://learnmem.cshlp.org/content/14/10/673.full.html\#related-urls

License

Email Alerting Receive free email alerts when new articles cite this article - sign up in the box at the Service top right corner of the article or click here. 